(2) Open Access Full Text Article

REVIEW

\title{
Improved understanding of factors driving methicillin-resistant Staphylococcus aureus epidemic waves
}

This article was published in the following Dove Press journal:

Clinical Epidemiology

3 July 2013

Number of times this article has been viewed

\author{
Som S Chatterjee \\ Michael Otto \\ Pathogen Molecular Genetics \\ Section, National Institute of Allergy \\ and Infectious Diseases, Bethesda, \\ MD, USA
}

\begin{abstract}
Methicillin-resistant Staphylococcus aureus (MRSA) remains one of the most important causes of nosocomial infections worldwide. Since the global spread of MRSA in the 1960s, MRSA strains have evolved with increased pathogenic potential. Notably, some strains are now capable of causing persistent infections not only in hospitalized patients but also in healthy individuals in the community. Furthermore, MRSA is increasingly associated with infections among livestock-associated workers, primarily because of transmission from animals to humans. Moreover, many MRSA strains have gained resistance to most available antibiotics. In this review, we will present current knowledge on MRSA epidemiology and discuss new endeavors being undertaken to understand better the molecular and epidemiological underpinnings of MRSA outbreaks.
\end{abstract}

Keywords: Staphylococcus aureus, MRSA, nosocomial infection, community-associated infection

\section{Introduction}

Infection caused by bacterial pathogens is a global problem. In many cases, bacterial resistance to antimicrobial agents may considerably complicate treatment. ${ }^{1}$ Several infectious strains have acquired resistance toward most available antibiotics, which warrants global surveillance and antimicrobial stewardship in addition to increased research efforts to understand the mechanisms underlying pathogenesis and antimicrobial resistance. This is especially true in the case of methicillin-resistant Staphylococcus aureus (MRSA) which is one of the most prominent pathogens associated with hospital-, community-, and livestock-associated infections. ${ }^{2}$ In this review, we discuss the epidemiology, pathophysiology, and impact on clinical practice of MRSA infections. In addition to this, we highlight important recent research efforts aimed at bettering understanding the key factors that drive MRSA epidemics.

\section{History of MRSA}

S. aureus has been associated with human infections since prehistoric times. ${ }^{3}$ Due to its prominence as a health-care-related pathogen, it has been a cause of serious concern for clinicians for over a century. ${ }^{4}$ Following the introduction of penicillin in the 1940 s, the first antimicrobial drug of its kind showing high effectiveness against staphylococcal infections, $S$. aureus developed penicillin resistance within a few months. ${ }^{5,6}$ The molecular determinant responsible for penicillin resistance was shown to be a plasmid-encoded $\beta$-lactamase gene capable of cleaving the $\beta$-lactam ring of penicillin. ${ }^{7,8}$ Within about two decades, penicillin resistance in $S$. aureus became a global problem. ${ }^{9}$
Correspondence: Michael Otto Pathogen Molecular Genetics Section, Laboratory of Human Bacterial Pathogenesis, National Institute of Allergy and Infectious Diseases, US National Institutes of Health, 9000 Rockville Pike, Bethesda, MD 20892, USA

$\mathrm{Tel}+\mathrm{I}$ 30I 4435209

$\mathrm{Fax}+$ I 30I 4803632

Email motto@niaid.nih.gov 
Methicillin, a semisynthetic derivative of penicillin that is resistant to cleavage by $\beta$-lactamase, was introduced into clinical use in 1959. Soon afterwards, infections caused by penicillin-resistant strains sharply declined. ${ }^{10}$ However, within just 2 years following the introduction of methicillin, the first MRSA strains were isolated in hospitals in the UK. ${ }^{11}$ Thereafter, MRSA became endemic worldwide. ${ }^{4}$ The molecular determinant of methicillin resistance in MRSA was later shown to be a mobile genetic element (MGE), staphylococcal chromosome cassette mec (SCCmec), ${ }^{12}$ which harbors the mec $A$ gene encoding a penicillin-binding protein (PBP2a/PBP2') with reduced affinity towards methicillin. ${ }^{13,14}$ As a result, methicillin cannot bind to the bacterial cell efficiently, leading to reduced capacity to inhibit bacterial cell-wall synthesis.

Of note, the term MRSA is used loosely, since methicillin sensu stricto is no longer applied in health-care settings. According to the Centers for Disease Control and Prevention, the definition of MRSA spans resistance of $S$. aureus not only against methicillin but also other related, more common antibiotics such as oxacillin and amoxicillin. Furthermore, $m e c A$ also provides general resistance to many $\beta$-lactam antibiotics, such as the penicillins. Moreover, SCCmec elements may also contain genes responsible for resistance to a wide array of antimicrobials besides $\beta$-lactams.

\section{Emergence of CA-MRSA and LA-MRSA}

While MRSA infections were observed sporadically in the community among individuals who had had recent exposure to health-care settings or had been in close contact with MRSAinfected individuals, ${ }^{15}$ MRSA was considered to be primarily a health-care-associated threat until the late 1990s. At that time, a dramatic shift in the MRSA target population occurred, as otherwise healthy individuals in the community developed MRSA infections in quickly increasing numbers. ${ }^{2,16-18}$ The first case of community-associated MRSA (CA-MRSA) was reported in 1993 in a remote part of Western Australia lacking any close health-care facility. ${ }^{19}$ Shortly thereafter, CA-MRSA appeared in the US, causing the deaths of four children in the Upper Midwest region. ${ }^{20,21}$ The history of the onset of CA-MRSA in the US has been reviewed elsewhere in great detail, 2,5,16,17 and thus will not be the subject of further discussion here. Currently, a persistently high number of CA-MRSA infections are being observed, in particular in the US, but also in increasing frequency in other parts of the world, reaching pandemic proportions. ${ }^{16,22,23}$ The fact that the CA-MRSA epidemic is particularly severe in the US is likely due to the high pathogenic potential of the US epidemic CA-MRSA strain USA300, which is now also spreading to other countries. The superiority of USA300 over other CA-MRSA strains may be due to a specific MGE, termed arginine catabolic mobile element (ACME), which harbors genes involved in pathogen survival on the human skin. ${ }^{24,25}$

Hospital-associated (HA-) and CA-MRSA are defined based on their distinctive association with the hospital or community settings, respectively. According to the current definition, CA-MRSA infections are those for which the onset of infection is within 48 hours of admission to the hospital with no previous history of hospitalization in the past year, whereas HA-MRSA is defined by the onset of infection occurring after 48 hours of hospital admission. ${ }^{26}$ The successful transfer of strains from the hospital to the community and vice versa has occurred, leading to "community-acquired hospital onset" and "hospital-acquired community onset" MRSA infections. ${ }^{27,28}$ For that reason, some authors have suggested that CA-MRSA cannot be clearly distinguished anymore from HA-MRSA. ${ }^{29}$ However, one has to be aware that the CA-/HA-MRSA definition is clinical, not microbiological. While specific strains are typically associated with CA-MRSA infections, the mere identification of the infective isolate as, for example, USA300 does not make an infection a CA-MRSA infection.

At present, an increasing number of reports from the US and abroad indicate that CA-MRSA strains are gradually replacing HA-MRSA strains in hospitals. Several authors have suggested that this indicates yet another potential epidemiological shift in staphylococcal infections. ${ }^{30-32}$ Nevertheless, the traditional hospital-associated strains, such as those of the USA100 and USA200 lineages, are still highly prevalent in hospitals, indicating that they are well adapted to that setting. ${ }^{33,34}$

$S$. aureus has also long been associated with severe infections in a variety of economically important livestock animals, including poultry, pigs, and cattle. ${ }^{35-38}$ MRSA in particular has been increasingly associated with livestock-associated (LA-MRSA) infections over the last 40 years. ${ }^{39-42}$ Although MRSA strains caused widespread infections among livestock animals, they showed distinct host tropism. ${ }^{43,44}$ However, the notion that $S$. aureus strains have evolved to thrive within a single species ${ }^{45}$ was recently challenged by reports of LA-MRSA strains infecting livestock-associated workers, ${ }^{46}$ human-to-poultry-transfer of sequence type (ST)-5 strains, ${ }^{42}$ and transmission of such strains as USA100, USA300, and USA500 between humans and their companion animals. ${ }^{47-53}$ Thus, the recent breach 
of the genus barrier by LA-MRSA strains points towards remarkable host adaptability of LA-MRSA and indicates that livestock animals can serve as a reservoir for infections in humans.

\section{Target population, transmission, and pathology of infection}

$S$. aureus is a frequent asymptomatic colonizer of humans. Roughly a third of the human population carries $S$. aureus, primarily in the nose, ${ }^{54,55}$ but also in other body parts, such as the nasopharynx, groin, and perineum. ${ }^{56}$ The occurrence of MRSA colonization in the human population is estimated to be about $1.5 \%$, of which roughly one in six carries a CA-MRSA strain. ${ }^{57,58}$ Recent epidemiological data suggest that CA-MRSA carriage is on the rise in the human population. ${ }^{59}$

There are several risk factors for the acquisition of an MRSA infection. Generally, an individual is at high risk for infection from his or her own colonizing strain. ${ }^{60}$ The transmission of the bacteria from an infected to a noninfected individual takes place either by direct skin-to-skin contact with an infected person or through contaminated fomites in public and household settings. ${ }^{61,62}$ Poor personal hygiene and a compromised skin barrier are believed to play important roles in developing infection in the community, while underlying conditions such as a compromised immune system increase the risk for MRSA infection during hospitalization. MRSA is prevalent in health-care workers, ${ }^{63}$ indicating that these workers might serve as a reservoir for the spread of HA-MRSA infections in hospitals. Close contact with infected livestock and companion animals is a direct cause of LA-MRSA infections in humans. ${ }^{64,65}$

The target population of MRSA infections is diverse. Groups at high risk for CA-MRSA infections include prison inmates, military personnel, ${ }^{66}$ athletes, ${ }^{62}$ intravenous drug users, ${ }^{9}$ and men who have sex with men. ${ }^{67}$ The elderly, children, ${ }^{68}$ patients with indwelling medical devices, ${ }^{69}$ people with underlying disease conditions such as diabetes ${ }^{70}$ or neutrophil dysfunction, ${ }^{71} \mathrm{HIV} / \mathrm{AIDS}$ patients, ${ }^{72,73}$ and individuals who have had a recent history of influenza are at high risk primarily for HA-MRSA infection.

MRSA disease manifestations are equally diverse with regard to seriousness and scope. Mild-to-severe skin and softtissue infections are among the most common MRSA-related diseases. ${ }^{74}$ However, serious medical complications, such as dermatitis, ${ }^{75}$ osteomyelitis, ${ }^{76}$ necrotizing pneumonia, ${ }^{77}$ ventilator-associated pneumonia, ${ }^{78}$ endocarditis, ${ }^{79}$ and bloodstream infections (BSIs) ${ }^{80}$ may be caused by MRSA. MRSA-related BSI is the highest cause of mortality in the US among bacterial BSI ${ }^{81}$ While most CA-MRSA infections are usually infections of the skin and soft tissues, CA-MRSA may also cause severe infections, such as necrotizing pneumonia or necrotizing fasciitis. ${ }^{74}$ LA-MRSA infections in livestock animals include leg weakness in boiler chickens, abscess and septicemia in rabbits, dermatitis in pigs, and mastitis in cattle. ${ }^{35,37,38,82}$

\section{Global epidemic status and economic burden}

MRSA is the most prominent cause of nosocomial infections caused by a single bacterial pathogen in the US and many parts of the world..$^{27,83-85}$ It is estimated that about $44 \%$ of all hospital-associated infections can be attributed to MRSA. ${ }^{86}$ Recent estimates suggest that in the US, the mortality due to MRSA infections is higher than that due to HIV/AIDS. ${ }^{87}$

The severity of infections caused by MRSA is thought to be higher than that caused by methicillin-sensitive $S$. aureus (MSSA) ${ }^{88}$ not because MRSA strains are in general more virulent, but because they offer fewer therapeutic options. Mounting evidence suggests that MRSA infections lead to a longer stay in hospitals, which in turn leads to higher costs. ${ }^{89,90}$ According to recent estimates, general MRSA infections resulted in 1 million extra days of hospitalization in the EU, corresponding to US\$570 million of additional costs. ${ }^{86}$ In the US, the cost per MRSA infection is thought to be $\$ 12,000,{ }^{86,91}$ and a delay in the diagnosis of MRSA bacteremia attributes to costs ranging between $\$ 3,800$ and $\$ 27,000$ per patient. ${ }^{92,93}$ Furthermore, MRSA-related cases of osteomyelitis, ${ }^{94}$ outbreaks in neonatal intensive care units, ${ }^{95}$ and infections of indwelling medical devices ${ }^{96}$ appear to be on the rise in hospitals.

CA-MRSA is a significant public health threat ${ }^{97}$ and considered to be the most frequent cause for visits to emergency rooms in the US. ${ }^{98}$ Currently, CA-MRSA is endemic in Sri Lanka, Taiwan, People's Republic of China, the Philippines, Vietnam, Australia, Greece, and the UK, besides the US. ${ }^{4,26,99}$ Worldwide, most CA-MRSA cases are mild soft-tissue infections, although requirement for hospitalization due to severe adult cases of communityassociated skin and soft-tissue infection (SSTI) remains high and is estimated to be between $16 \%$ and $44 \% .{ }^{100}$ SSTIs are increasing in frequency in the US, ${ }^{101}$ mostly because of CA-MRSA and the recurrent nature of CA-MRSA infections. ${ }^{102}$ Of note, SSTI can serve as a source of BSI and hence higher health-care-related cost per patient. ${ }^{80}$ 


\section{Current treatment of MRSA}

The treatment of MRSA infections is becoming increasingly more complicated due to increasing resistance to antimicrobials and strain diversity. Thus, treatment of MRSA infections is gradually getting geared towards personalized therapy.

In general, therapy for serious MRSA infections involves a multistep process. At first, debridement of the infecting MRSA strain is required, which includes drainage of the contaminated tissue or removal of the infected medical device. Prompt debridement or removal of the infection foci improves the outcome ${ }^{103,104}$ and prevents the relapse of infection. ${ }^{104,105}$ Along with debridement, laboratory tests are performed on the infecting bacterial strain to determine its antibiogram (ie, antibiotic susceptibility). The antibiogram dictates the type of antimicrobial therapy. The Infectious Disease Society of America (IDSA) has set forth a detailed methodological guideline for clinical care of MRSA infections. ${ }^{106}$

Due to their efficiency, $\beta$-lactams are the antibiotics of first choice for staphylococcal infections. However, with MRSA rates becoming increasingly higher and less than 5\% of clinical strains being sensitive to penicillins, ${ }^{4}$ the treatment of $S$. aureus infection now relies increasingly on non- $\beta$ lactam-based antibiotics. ${ }^{107}$ Although vancomycin is inferior to $\beta$-lactam drugs ${ }^{108}$ in terms of potency in sterilizing the blood, ${ }^{109,110}$ and toxic effects to kidneys, ${ }^{111}$ it is the preferred drug for the treatment of MRSA infections. ${ }^{112}$ Unfortunately, resistance to vancomycin already exists. According to the Clinical and Laboratory Standards Institute, vancomycinsensitive $S$. aureus, vancomycin-intermediate $S$. aureus (VISA), and vancomycin-resistant $S$. aureus (VRSA) are defined by bacterial inhibition at doses of $<4 \mathrm{mg} / \mathrm{mL}$, $4-8 \mathrm{mg} / \mathrm{mL}$, and $\geq 16 \mathrm{mg} / \mathrm{mL}$, respectively. ${ }^{113,114}$ While VRSA has remained very rare, VISA is on the rise in the US. ${ }^{115,116}$ High-level resistance to vancomycin in VRSA is due to the acquisition of the van $A$ gene,,${ }^{117}$ while intermediate resistance is multifactorial and due to genetic alterations that increase the thickness of the cell wall. ${ }^{118}$

Apart from vancomycin, linezolid, daptomycin, and tigecycline are FDA-approved and effective against MRSA infections. ${ }^{100,119}$ Notably, daptomycin is ineffective against pulmonary infections. ${ }^{120}$ In addition, improved $\beta$-lactams such as cephalosporins (ceftaroline/ceftobiprole), carbapenems, long-acting tetracyclines (doxycyclines/minocyclines), clindamycin, rifampin, and improved glycopeptides (telavancin) are used to treat mild-to-severe MRSA infections, either alone or in combination therapies. ${ }^{121-123}$

The therapy to be used against an MRSA infection is often determined by the nature and severity of the infection.
In cases of mild CA-MSRA skin infections, inexpensive oral agents are recommended. Clindamycin and doxycycline are good choices in this regard, ${ }^{124,125}$ and are recommended in children with mild CA-MRSA-associated SSTI infections. ${ }^{126}$ For less severe bacteremia or endocarditis, vancomycin together with a semisynthetic penicillin is the treatment of choice. When the infecting isolate shows a resistance level to vancomycin of $>1 \mathrm{mg} / \mathrm{mL}$ or in cases of renal failure, daptomycin or linezolid are recommended. Linezolid is particularly favorable in cases of ventilator-associated and hospital-associated pneumonia. ${ }^{127}$ The IDSA set forward clear guidelines for the treatment of MRSA infections. Vancomycin/daptomycin is the preferred drug for bacteremia and endocarditis, vancomycin/daptomycin along with rifampin for prosthetic valve infections, and vancomycin/ linezolid/clindamycin for HA/CA-MRSA pneumonia.

The drugs currently used to treat MRSA infections are progressively showing decreasing efficacy due to increasing bacterial resistance. Several cases of $S$. aureus resistance to "last-resort drugs," such as vancomycin, daptomycin, and linezolid, have been reported, ${ }^{128-131}$ which calls for the development of new and improved anti-MRSA drugs. Several new drugs are under development, such as carbapenems (cefonicid, ceftazidime), quinolones, and glycopeptides (dalbavancin, oritavancin). ${ }^{132}$ Unfortunately, vaccine-intervention strategies against $S$. aureus have failed so far. An alternative vaccine approach targeting virulence determinants has gained momentum in recent times. Staphylococcal $\alpha$-toxin, Panton-Valentine leukocidin (PVL), leukocidin ED, and the recently described phenol-soluble modulin (PSM) transporter could serve as potential targets for such an approach (see below).

\section{MRSA typing}

There has been a persistent effort to understand the epidemiology of S. aureus by typing the infective isolates, for which a number of molecular methods are currently in practice. ${ }^{12,133}$ While all methods provide valuable information regarding staphylococcal phylogeny, some are predominantly directed to decipher bacterial microevolution, such as multilocus sequence typing (MLST) and staphylococcal protein A (spa) gene typing, whereas others, such as pulsed-field gel electrophoresis (PFGE) and SCCmec typing, yield more information about large genetic changes, such as gene deletions or duplications.

MLST is based on the sequence analysis of 450-base-pair internal fragments of seven housekeeping genes. Isolates showing sequence similarity in all seven genes are given 
a unique ST number, and closely related STs are grouped together in a single clonal complex (CC). Spa typing is based on the sequencing of the polymorphic $\mathrm{X}$ region of the spa gene. ${ }^{134}$ Both MLST and spa typing are currently centralized and automated (for MLST, http://saureus.mlst. net; for spa typing, http://www.egenomics.com or http:// spaserver.ridom.de).

PFGE is the analysis of DNA fragments following SmaI digestion of the bacterial genome on an agarose gel. PFGE is highly reliable and a gold standard for strain designations. ${ }^{135}$ However, low portability of data along with regional description of PGFE patterns (in the US, USA100 or USA200 etc; in Australia, WMRSA; in the UK, EMRSA; and in Canada, CMRSA) make it difficult to compare isolates.

SCCmec is an MGE of 21-67 kb in length that contains the mecA gene. Currently, there are eleven different allotypes of SCCmec - types I-XI (http://www.sccmec.org) among $S$. aureus strains - of which SCCmec type III is the largest and SCCmec type IV the smallest. Due to its smaller size, $\mathrm{SCCmec} \mathrm{IV} \mathrm{is} \mathrm{thought} \mathrm{to} \mathrm{give} \mathrm{a} \mathrm{fitness} \mathrm{advantage} \mathrm{compared}$ to other SCCmec types. ${ }^{136,137}$. Usually HA-MRSA isolates carry SCCmec types I, II, or III, whereas CA-MRSA isolates possess SCCmec types IV, V, or VII. ${ }^{138}$

\section{Epidemiology of MRSA epidemic waves}

$S$. aureus infection rates rise and fall in epidemic waves. Epidemic waves are rapid and widespread outbursts of $S$. aureus infections affecting many individuals in an area or population. The causes underlying the appearance and disappearance of $S$. aureus epidemics are largely unknown, but likely comprise exposure to a new antibacterial agent, or in some cases lifestyle habits. ${ }^{2}$

\section{Epidemic wave I (1950s, phage type $80 / 81$, penicillin-resistant strains)}

This first recorded outbreak was caused by penicillin-resistant strains of the phage type 80/81 lineage, following the introduction of penicillin in the 1940s. It started in the UK, and in the 1950s had become a worldwide problem. ${ }^{139}$

\section{Epidemic wave 2 (I960s, archaic MRSA)}

This outbreak was due to the spread of the first MRSA clones, shortly following the introduction of methicillin. It caused mostly serious health-care-associated infections, but also occasionally mild community-associated infections throughout Europe. ${ }^{11}$

\section{Epidemic wave 3 (I980s, toxic-shock} syndrome clones)

Toxic-shock syndrome (TSS), also referred to as staphylococcal scarlet fever, was first reported in 1978 among young menstrual women. ${ }^{140}$ The following years saw a severe outbreak of TSS cases, with the use of superabsorbent tampons soon discovered to be the underlying risk factor. ${ }^{141}$ The exotoxin encoded by the $t$ ts gene was identified as the single molecular determinant of TSS. ${ }^{142}$

\section{Epidemic wave 4 (1980s until present, HA-MRSA)}

This outbreak followed the rise of a novel MRSA lineage, called Iberian or Rome clone, which became pandemic in the hospitals. Several other strains of $S$. aureus, such as USA100, USA200, EMRSA-15, and EMRSA-16, emerged as further common HA-MRSA strains and continue to cause a high number of nosocomial infections worldwide..$^{2,143,144}$

\section{Epidemic wave 5 (1990s until present, CA-MRSA)}

This epidemic started in Western Australia with the discovery of the first case of CA-MRSA caused by the WA-1 or WA-MRSA1 strain. A close relative of the WA-1 strain, the USA400 strain, soon became widespread in the US and Canada. ${ }^{19,145}$ This epidemic wave constitutes two overlapping waves, the first of which was prevalent until 2001 and caused by the USA400 strain. This was followed by the current CA-MRSA pandemic caused by the USA300 strain. Currently, USA300 is the major cause of CA-MRSA infections in many countries, including the US, ${ }^{146}$ while infections due to USA400 strains are restricted mainly to Alaska and the Pacific Northwest. ${ }^{2}$

\section{Epidemic wave 6 (early 2000s} LA-MRSA outbreak)

This outbreak in humans is caused by a pig-associated MRSA isolate of the CC398 lineage. LA-MRSA was first reported in Europe, but is currently pandemic and can sometimes cause serious infections among healthy livestock workers and veterinarians. The LA-MRSA pandemic exemplifies a rare but increasingly occurring case of shared infection between animals and humans. ${ }^{29,30}$

\section{Worldwide emergence of epidemic MRSA strains}

The majority of MRSA infections are caused by strains belonging to a few CCs. The most prevalent are CC1 (USA400), CC5 
(USA100 or NY/Japan clone, USA800 or pediatric clone), CC8 (Col, Iberian clone, USA300, and USA500), CC22 (EMRSA-15), CC30 (USA200, EMRSA-16, USA1100, the Southwest Pacific Oceania clone), CC45 (USA600, Berlin clone), CC59 (Taiwan), and CC80 (Europe). ${ }^{2,133}$ Of these, CCs $1,5,8,22,30$, and 45 are prominent in the hospitals, whereas CCs $1,8,22,30,59$, and 80 are mostly prevalent in the community. MRSA strains representing CCs 8 and 30 are pandemic both in the hospitals and in the community, and are among the most frequently isolated strains from infections. CC 22 and 30 represented by ST22 (EMRSA-15) and ST36 (EMRSA-16) strains are prevalent in the UK. All known VISA strains belong to CC5. The archaic and Iberian MRSA, USA400, and USA300 strains belong to CC8. Of note, these representative CCs are not exclusive to MRSA, but also include MSSA strains. For example, the phage type 80/81strains discussed above belong to CC30. Finally, there are some regional clones, such as ST772 (Bengal Bay clone), which is mostly prevalent in Bangladesh and India, ${ }^{147}$ ST72 strains in South Korea, the Caribbean, and Portugal, and ST88 strains in Africa and Asia. ${ }^{133,148,149}$

\section{Emergence and dominance of USA300 in current CA- and HA-MRSA infections}

USA300 has emerged as the dominant CA-MRSA strain in the US. ${ }^{31}$ First isolated in 2000, it was traditionally a communityassociated strain, ${ }^{150}$ but it now also represents a major threat to patients in hospitals and long-term care facilities. ${ }^{32,151}$ Additionally, USA300 is increasingly responsible for the majority of CA-MRSA infections worldwide, including in Canada, Europe, Australia, Japan, and Latin America. ${ }^{146,152-154}$

Consistent with USA300's global dominance, laboratory experiments show elevated virulence of this strain compared to contemporary MRSA isolates. ${ }^{155,156}$ Notably, the USA300 strains in the US are highly clonal and closely genetically related. ${ }^{157}$ While the evolution of CA-MRSA virulence, and in particular that of USA300, is a matter of ongoing debate, ${ }^{18}$ the enormous success of USA300 is attributed generally to increased resistance of USA300 to antimicrobial agents, ${ }^{67,158,159}$ increased expression of virulence genes ${ }^{156}$ and their regulators, higher persistence, ${ }^{25}$ and acquisition of virulence determinants on MGEs, such as $\mathrm{PVL}^{160}$ (see below).

\section{Recent emergence of LA-MRSA}

The first case of LA-MRSA was reported in 1972 in cows. ${ }^{41}$ LA-MRSA is associated with a relatively small number of lineages. For example, bovine infections are caused predominantly by strains belonging to CC97, CC126, CC130, and ST151. CC398 and ST9 are predominantly present in pigs. The isolation of a novel mec $A$ gene ( $m e c A_{\mathrm{LGA} 251}$ ), also known as $m e c C,{ }^{161}$ from cattle suggests that LA-MRSA strains are distinct from HA- and CA-MRSA. Recently, bovine-specific LA-MRSA strains were isolated from humans in the UK, Denmark, and Germany, ${ }^{162}$ suggesting that cows can serve as a reservoir for human MRSA. Subsequently, several cases of LA-MRSA-mediated human infections were reported throughout the world. The underlying risk factor for these infections is primarily exposure to livestock. ${ }^{40}$

CC398 was first discovered in Europe in early 2000 and rapidly became the major cause of human LA-MRSA infections. Studies performed in Denmark and Belgium showed that livestock-associated veterinarians have a high chance of being infected by CC398 LA-MRSA strains. ${ }^{163}$ Presently, CC398-mediated LA-MRSA infections have reached pandemic proportions, as several cases have been reported from such geographically diverse locations as Canada, China, Colombia, and the Caribbean. ${ }^{148,164,165}$ In the Netherlands, human cases of CC398 infections represent $25 \%$ of total MRSA infections. ${ }^{166}$ Pigs are thought to be the major asymptomatic carriers of CC398 clones $^{167}$; however, CC398 strains have also occurred in cows, veal, poultry, horses, and dogs. ${ }^{46}$ CC398 clones show high diversity. ${ }^{168}$ Interestingly, cases of CC398 MSSA strains colonizing healthy individuals have been reported in the US. ${ }^{169}$ Recent research indicates that the CC398 LA-MRSA strains may have been derived from a human MSSA CC398 isolate that was transferred to pigs, where it obtained the SCCmec cluster. ${ }^{168}$

\section{Evolution of MRSA pathogenic success}

The success of $S$. aureus as a pathogen is to a large extent due to its ability to resist antimicrobial agents and circumvent the immune surveillance of the host. Many molecular determinants of resistance and virulence in $S$. aureus are encoded on MGEs. The presence of those factors is thus highly strain-dependent, while some core genome-encoded virulence determinants are present in virtually all strains.

The commonly MGE-encoded determinants of antimicrobial resistance have already been discussed in previous sections. In addition, $S$. aureus possesses an enormous repertoire of virulence and persistence genes that may be genome- or MGE-encoded. In this article, only a selected few are presented. The reader is referred to review 
articles presenting the molecular basis of $S$. aureus virulence in more detail. ${ }^{18,170}$

The core genome-encoded pore-forming toxin, $\alpha$-toxin, is produced by most $S$. aureus strains. $\alpha$-Toxin is proinflammatory, shows cytolytic effects to various immune cells except human neutrophils, ${ }^{171}$ and is critical for $S$. aureus virulence in various animal models of infection. ${ }^{172,173}$ Vaccination with a nontoxic $\alpha$-toxin variant provides protection against staphylococcal pneumonia and skin infection. ${ }^{174,175}$

PSMs are a group of small, core genome-encoded amphipathic peptides of $\sim 20-45$ amino acids. They are present in all $S$. aureus strains and considered key determinants in the development of skin, bloodstream, and biofilm-associated infections. ${ }^{176,177}$ In particular $\alpha$-type PSMs are strongly cytolytic toward neutrophils and erythrocytes at the micromolar range. ${ }^{176}$ Notably, PSM $\alpha$ peptides of $S$. aureus destroy neutrophils after phagocytosis from within the neutrophil phagosome. ${ }^{178,179}$ At nanomolar concentrations, all PSMs are proinflammatory by receptor-mediated interaction. ${ }^{176,180}$ The PSM-secretion machinery in $S$. aureus has recently been identified, ${ }^{179}$ potentially representing a target for simultaneous interference with all PSMs.

Leukotoxins are perhaps the most extensively studied staphylococcal virulence determinants in recent times. Clinical strains of $S$. aureus may produce four different types of bicomponent leukotoxins, namely PVL, $\gamma$-hemolysin, leukotoxin ED, and/or leukotoxin $\mathrm{AB} / \mathrm{GH} .{ }^{181}$ Apart from $\gamma$-hemolysin, they are all MGE-encoded. ${ }^{182}$ All leukotoxins are proinflammatory and show cytolytic activity towards neutrophils, with considerable host specificity. ${ }^{183-186}$ Recently, the CCR5 receptor was shown to recognize leukotoxin ED, ${ }^{187}$ suggesting that in contrast to previous belief, the cytolytic activities of - possibly all - staphylococcal leukotoxins are receptor-dependent.

ACME harbors a set of genes that enable the bacteria to utilize arginine present on human skin to their metabolic advantage and detoxify host-derived antimicrobial agents. ${ }^{24,25}$ Of note, ACME, likely acquired from $S$. epidermidis, is exclusively present in the USA300 background among S. aureus strains, potentially explaining the superiority of USA300 over other CA-MRSA strains.

\section{Current efforts in understanding molecular MRSA epidemiology}

There has been a recent emphasis on understanding MRSA epidemic waves on the molecular level. In a rare effort to combine epidemiological and functional analyses for that purpose, an $S$. aureus MGE-encoded factor, the surface protein SasX, was identified to be significantly increasing in frequency among Asian HA-MRSA strains. Notably, SasX was found to be associated with increased nasal colonization, immune evasion and virulence. ${ }^{188}$ Furthermore, genome comparison of the pandemic phage type 80/81 strain with that of a contemporary CC30 HA-MRSA strain showed that a truncated $\alpha$-toxin gene and mutated $\operatorname{agr} C$ led to a reduction in aggressive virulence in the contemporary HA-MRSA CC30 background, possibly explaining the success of those clones in the hospital environment. ${ }^{189}$ Further genomewide studies were recently performed to document the evolution of bacterial resistance to vancomycin and linezolid within patients during antimicrobial therapy. ${ }^{190-193}$ Several longitudinal studies with isolates from cystic fibrosis, ${ }^{194}$ persistent infections in households, ${ }^{195}$ and an MRSA clone before and after $\mathrm{BSI}^{196}$ revealed several subtle genetic changes compromising virulence, cell-wall biosynthesis, and antimicrobial resistance. All these studies suggest that minor genetic adaptations may contribute to the development of MRSA fitness and persistence.

\section{Current surveillance efforts}

Active surveillance of MRSA with guidelines for proper treatment and documentation of hospital-associated MRSA cases is performed in many countries. The so-called searchand-destroy approach to deal with MRSA cases is practiced in many parts of Europe, including the Scandinavian countries and the Netherlands. It involves the routine screening of patients and health-care personnel for MRSA, and has proved to be highly successful. ${ }^{197,198}$ Because poor hygiene correlates with a higher prevalence of MRSA, and improper use of antibiotics with a higher MRSA carriage, ${ }^{199}$ the control of MRSA includes cost-effective sanitizing methods, such as proper hand-washing and an overall restrained use of antibiotics. Recent clinical data show that HA-MRSA cases have been on a decline in the US between 2005 and $2008^{200}$ and in the UK since 2006, probably due at least in part to these measures, and in the latter case the mandatory surveillance of MRSA. ${ }^{201,202}$

\section{Concluding remarks}

Half a century after its surge, MRSA remains a serious threat to public health-care systems worldwide. MRSA strains have gained resistance to a variety of antibiotics, and an S. aureus vaccine is not available or in sight. Owing to the low fitness cost associated with methicillin resistance and the relatively easy transmission from infected individuals or fomites, the bacteria can spread easily. The surge in global travel over 
the last few decades has added to the spread of MRSA. It is now a generally accepted view that proper management of the MRSA problem needs a multipronged approach. This approach should include global surveillance of MRSA, development of new and improved antimicrobial agents, and increased understanding of MRSA pathophysiology through basic scientific research.

\section{Acknowledgments}

This work was supported by the Intramural Research Program of the National Institute of Allergy and Infectious Diseases (NIAID), US National Institutes of Health (NIH).

\section{Disclosure}

The authors report no conflicts of interest in this work.

\section{References}

1. Mishra RP, Oviedo-Orta E, Prachi P, Rappuoli R, Bagnoli F. Vaccines and antibiotic resistance. Curr Opin Microbiol. 2012;15:596-602.

2. Chambers HF, DeLeo FR. Waves of resistance: Staphylococcus aureus in the antibiotic era. Nat Rev Microbiol. 2009;7:629-641.

3. Moellering RC Jr. Past, present, and future of antimicrobial agents. Am J Med. 1995;99:11S-18S.

4. Lowy FD. Staphylococcus aureus infections. N Engl J Med. 1998;339: 520-532.

5. Kirby H. Une faute de transcription, d'orthographe, ou d'impression. Science. 1944;100:425-427.

6. Demerec M. Production of Staphylococcus strains resistant to various concentrations of penicillin. Proc Natl Acad Sci U S A. 1945;31:16-24.

7. Murray BE, Moellering RC Jr. Patterns and mechanisms of antibiotic resistance. Med Clin North Am. 1978 62:899-923.

8. Abraham EP, Chain E. An enzyme from bacteria able to destroy penicillin. 1940. Rev Infect Dis. 1988;10:677-678.

9. Rountree PM, Freeman BM, Barbour RG. Nasal carriage of Staphylococcus aureus in the general population and its relationship to hospitalization and to penicillin therapy. Med J Aust. 1954;2:457-460.

10. Jevons MP, Parker MT. The evolution of new hospital strains of Staphylococcus aureus. J Clin Pathol. 1964;17:243-250.

11. Jevons MP, Rolinson GN, Knox R. Celbenin-resistant staphylococci. BMJ. 1961;1:124-126.

12. Matsuhashi M, Song MD, Ishino F, et al. Molecular cloning of the gene of a penicillin-binding protein supposed to cause high resistance to beta-lactam antibiotics in Staphylococcus aureus. J Bacteriol. 1986;167: 975-980.

13. Murakami K, Tomasz A. Involvement of multiple genetic determinants in high-level methicillin resistance in Staphylococcus aureus. J Bacteriol. 1989;171:874-879.

14. Ito T, Katayama Y, Hiramatsu K. Cloning and nucleotide sequence determination of the entire mec DNA of pre-methicillin-resistant Staphylococcus aureus N315. Antimicrob Agents Chemother. 1999;43: 1449-1458.

15. Charlebois ED, Perdreau-Remington F, Kreiswirth B, et al. Origins of community strains of methicillin-resistant Staphylococcus aureus. Clin Infect Dis. 2004;39:47-54.

16. DeLeo FR, Otto M, Kreiswirth BN, Chambers HF. Community-associated meticillin-resistant Staphylococcus aureus. Lancet. 2010;375: 1557-1568.

17. DeLeo FR, Chambers HF. Reemergence of antibiotic-resistant Staphylococcus aureus in the genomics era. J Clin Invest. 2009;119: 2464-2474.
18. Otto M. Basis of virulence in community-associated methicillin-resistant Staphylococcus aureus. Annu Rev Microbiol. 2010;64:143-162.

19. Udo EE, Pearman JW, Grubb WB. Genetic analysis of community isolates of methicillin-resistant Staphylococcus aureus in Western Australia. J Hosp Infect. 1993;25:97-108.

20. [No authors listed]. From the Centers for Disease Control and Prevention. Four pediatric deaths from community-acquired methicillin-resistant Staphylococcus aureus - Minnesota and North Dakota, 1997-1999. JAMA. 1999;282:1123-1125.

21. Herold BC, Immergluck LC, Maranan MC, et al. Community-acquired methicillin-resistant Staphylococcus aureus in children with no identified predisposing risk. JAMA. 1998;279:593-598.

22. Vandenesch F, Naimi T, Enright MC, et al. Community-acquired methicillin-resistant Staphylococcus aureus carrying Panton-Valentine leukocidin genes: worldwide emergence. Emerg Infect Dis. 2003;9:978-984.

23. Otto M. MRSA virulence and spread. Cell Microbiol. 2012;14: 1513-1521.

24. Joshi GS, Spontak JS, Klapper DG, Richardson AR. Arginine catabolic mobile element encoded speG abrogates the unique hypersensitivity of Staphylococcus aureus to exogenous polyamines. Mol Microbiol. 2011;82:9-20.

25. Thurlow LR, Joshi GS, Clark JR, et al. Functional modularity of the arginine catabolic mobile element contributes to the success of USA300 methicillin-resistant Staphylococcus aureus. Cell Host Microbe. 2013;13:100-107.

26. Skov R, Christiansen K, Dancer SJ, et al. Update on the prevention and control of community-acquired meticillin-resistant Staphylococcus aureus (CA-MRSA). Int J Antimicrob Agents. 2012;39: 193-200.

27. Scanvic A, Denic L, Gaillon S, Giry P, Andremont A, Lucet JC. Duration of colonization by methicillin-resistant Staphylococcus aureus after hospital discharge and risk factors for prolonged carriage. Clin Infect Dis. 2001;32:1393-1398.

28. Klevens RM, Morrison MA, Fridkin SK, et al. Community-associated methicillin-resistant Staphylococcus aureus and healthcare risk factors. Emerg Infect Dis. 2006;12:1991-1993.

29. Otter JA, French GL. Community-associated meticillin-resistant Staphylococcus aureus: the case for a genotypic definition. J Hosp Infect. 2012;81:143-148.

30. Jimenez JN, Ocampo AM, Vanegas JM, et al. CC8 MRSA strains harboring SCCmec type IVc are predominant in Colombian hospitals. PLoS One. 2012;7:e38576.

31. Tattevin P, Diep BA, Jula M, Perdreau-Remington F. Long-term follow-up of methicillin-resistant Staphylococcus aureus molecular epidemiology after emergence of clone USA300 in San Francisco jail populations. J Clin Microbiol. 2008;46:4056-4057.

32. Tattevin P, Diep BA, Jula M, Perdreau-Remington F. Methicillinresistant Staphylococcus aureus USA300 clone in long-term care facility. Emerg Infect Dis. 2009;15:953-955.

33. Tenover FC, Tickler IA, Goering RV, Kreiswirth BN, Mediavilla JR, Persing DH. Characterization of nasal and blood culture isolates of methicillin-resistant Staphylococcus aureus from patients in United States Hospitals. Antimicrob Agents Chemother. 2012;56: 1324-1330.

34. Abdel-Haq N, Al-Tatari H, Chearskul P, et al. Methicillin-resistant Staphylococcus aureus (MRSA) in hospitalized children: correlation of molecular analysis with clinical presentation and antibiotic susceptibility testing (ABST) results. Eur J Clin Microbiol Infect Dis. 2009;28:547-551.

35. Bradley A. Bovine mastitis: an evolving disease. Vet J. 2002;164: 116-128.

36. Menzies PI, Ramanoon SZ. Mastitis of sheep and goats. Vet Clin North Am Food Anim Pract. 2001;17:333-358, vii.

37. McNamee PT, Smyth JA. Bacterial chondronecrosis with osteomyelitis ('femoral head necrosis') of broiler chickens: a review. Avian Pathol. 2000;29:477-495. 
38. Vancraeynest D, Haesebrouck F, Deplano A, et al. International dissemination of a high virulence rabbit Staphylococcus aureus clone. J Vet Med B Infect Dis Vet Public Health. 2006;53:418-422.

39. Cuny C, Friedrich A, Kozytska S, et al. Emergence of methicillinresistant Staphylococcus aureus (MRSA) in different animal species. Int J Med Microbiol. 2010;300:109-117.

40. Armand-Lefevre L, Ruimy R, Andremont A. Clonal comparison of Staphylococcus aureus isolates from healthy pig farmers, human controls, and pigs. Emerg Infect Dis. 2005;11:711-714.

41. Devriese LA, Van Damme LR, Fameree L. Methicillin (cloxacillin)resistant Staphylococcus aureus strains isolated from bovine mastitis cases. Zentralbl Veterinarmed B. 1972;19:598-605.

42. Lowder BV, Guinane CM, Ben Zakour NL, et al. Recent human-topoultry host jump, adaptation, and pandemic spread of Staphylococcus aureus. Proc Natl Acad Sci U S A. 2009;106:19545-19550.

43. Musser JM, Schlievert PM, Chow AW, et al. A single clone of Staphylococcus aureus causes the majority of cases of toxic shock syndrome. Proc Natl Acad Sci U S A. 1990;87:225-229.

44. Devriese LA. A simplified system for biotyping Staphylococcus aureus strains isolated from animal species. JAppl Bacteriol. 1984;56: 215-220.

45. Kloos WE. Natural populations of the genus Staphylococcus. Annu Rev Microbiol. 1980;34:559-592.

46. Fluit AC. Livestock-associated Staphylococcus aureus. Clin Microbiol Infect. 2012;18:735-744.

47. Walther B, Wieler LH, Vincze S, et al. MRSA variant in companion animals. Emerg Infect Dis. 2012;18:2017-2020.

48. Petinaki E, Spiliopoulou I. Methicillin-resistant Staphylococcus aureus among companion and food-chain animals: impact of human contacts Clin Microbiol Infect. 2012;18:626-634.

49. Morris DO, Lautenbach E, Zaoutis T, Leckerman K, Edelstein PH, Rankin SC. Potential for pet animals to harbour methicillin-resistant Staphylococcus aureus when residing with human MRSA patients. Zoonoses Public Health. 2012;59:286-293.

50. Faires MC, Tater KC, Weese JS. An investigation of methicillinresistant Staphylococcus aureus colonization in people and pets in the same household with an infected person or infected pet. J Am Vet Med Assoc. 2009;235:540-543.

51. Coughlan K, Olsen KE, Boxrud D, Bender JB. Methicillin-resistant Staphylococcus aureus in resident animals of a long-term care facility. Zoonoses Public Health. 2010;57:220-226.

52. Haenni M, Chatre P, Boisset S, et al. Staphylococcal nasal carriage in calves: multiresistant Staphylococcus sciuri and immune evasion cluster (IEC) genes in methicillin-resistant Staphylococcus aureus ST398. J Antimicrob Chemother. 2011;66:1927-1928.

53. Lin Y, Barker E, Kislow J, et al. Evidence of multiple virulence subtypes in nosocomial and community-associated MRSA genotypes in companion animals from the upper midwestern and northeastern United States. Clin Med Res. 2011;9:7-16.

54. Graham PL 3rd, Lin SX, Larson EL. A US population-based survey of Staphylococcus aureus colonization. Ann Intern Med. 2006;144:318-325.

55. von Eiff C, Becker K, Machka K, Stammer H, Peters G. Nasal carriage as a source of Staphylococcus aureus bacteremia. Study Group. NEngl J Med. 2001;344:11-16.

56. Schechter-Perkins EM, Mitchell PM, Murray KA, Rubin-Smith JE, Weir S, Gupta K. Prevalence and predictors of nasal and extranasal staphylococcal colonization in patients presenting to the emergency department. Ann Emerg Med. 2011;57:492-499.

57. Gorwitz RJ, Kruszon-Moran D, McAllister SK, et al. Changes in the prevalence of nasal colonization with Staphylococcus aureus in the United States, 2001-2004. J Infect Dis. 2008;197:1226-1234.

58. Tenover FC, McAllister S, Fosheim G, et al. Characterization of Staphylococcus aureus isolates from nasal cultures collected from individuals in the United States in 2001 to 2004. J Clin Microbiol. 2008;46:2837-2841.

59. Creech CB 2nd, Kernodle DS, Alsentzer A, Wilson C, Edwards KM. Increasing rates of nasal carriage of methicillin-resistant Staphylococcus aureus in healthy children. Pediatr Infect Dis J. 2005;24:617-621.
60. Wenzel RP, Perl TM. The significance of nasal carriage of Staphylococcus aureus and the incidence of postoperative wound infection. J Hosp Infect. 1995;31:13-24.

61. Miller LG, Diep BA. Clinical practice: colonization, fomites, and virulence: rethinking the pathogenesis of community-associated methicillin-resistant Staphylococcus aureus infection. Clin Infect Dis. 2008;46:752-760.

62. Kazakova SV, Hageman JC, Matava M, et al. A clone of methicillinresistant Staphylococcus aureus among professional football players. N Engl J Med. 2005;352:468-475.

63. Elie-Turenne MC, Fernandes H, Mediavilla JR, et al. Prevalence and characteristics of Staphylococcus aureus colonization among healthcare professionals in an urban teaching hospital. Infect Control Hosp Epidemiol. 2010;31:574-580.

64. Jarvis WR, Schlosser J, Chinn RY, Tweeten S, Jackson M. National prevalence of methicillin-resistant Staphylococcus aureus in inpatients at US health care facilities, 2006. Am J Infect Control. 2007;35:631-637.

65. Fitzgerald JR. Livestock-associated Staphylococcus aureus: origin, evolution and public health threat. Trends Microbiol. 2012;20:192-198.

66. Aiello AE, Lowy FD, Wright LN, Larson EL. Meticillin-resistant Staphylococcus aureus among US prisoners and military personnel: review and recommendations for future studies. Lancet Infect Dis. 2006;6:335-341.

67. Diep BA, Chambers HF, Graber CJ, et al. Emergence of multidrugresistant, community-associated, methicillin-resistant Staphylococcus aureus clone USA300 in men who have sex with men. Ann Intern Med. 2008;148:249-257.

68. Adcock PM, Pastor P, Medley F, Patterson JE, Murphy TV. Methicillinresistant Staphylococcus aureus in two child care centers. J Infect Dis. 1998;178:577-580.

69. Kluytmans JA, Mouton JW, Ijzerman EP, et al. Nasal carriage of Staphylococcus aureus as a major risk factor for wound infections after cardiac surgery. J Infect Dis. 1995;171:216-219.

70. Tuazon CU, Perez A, Kishaba T, Sheagren JN. Staphylococcus aureus among insulin-injecting diabetic patients. An increased carrier rate. JAMA. 1975;231:1272.

71. Dinauer MC. Chronic granulomatous disease and other disorders of phagocyte function. Hematology Am Soc Hematol Educ Program. 2005:89-95

72. Shadyab AH, Crum-Cianflone NF. Methicillin-resistant Staphylococcus aureus (MRSA) infections among HIV-infected persons in the era of highly active antiretroviral therapy: a review of the literature. HIV Med. 2012;13:319-332.

73. Olsen RJ, Burns KM, Chen L, Kreiswirth BN, Musser JM. Severe necrotizing fasciitis in a human immunodeficiency virus-positive patient caused by methicillin-resistant Staphylococcus aureus. J Clin Microbiol. 2008;46:1144-1147.

74. Fridkin SK, Hageman JC, Morrison M, et al. Methicillin-resistant Staphylococcus aureus disease in three communities. $N$ Engl J Med. 2005;352:1436-1444

75. Trilla A, Miro JM. Identifying high risk patients for Staphylococcus aureus infections: skin and soft tissue infections. J Chemother. 1995; 7 Suppl 3:37-43.

76. Arnold SR, Elias D, Buckingham SC, et al. Changing patterns of acute hematogenous osteomyelitis and septic arthritis: emergence of community-associated methicillin-resistant Staphylococcus aureus. J Pediatr Orthop. 2006;26:703-708.

77. Francis JS, Doherty MC, Lopatin U, et al. Severe community-onset pneumonia in healthy adults caused by methicillin-resistant Staphylococcus aureus carrying the Panton-Valentine leukocidin genes. Clin Infect Dis. 2005;40:100-107.

78. Bassetti M, Trecarichi EM, Mesini A, et al. Risk factors and mortality of healthcare-associated and community-acquired Staphylococcus aureus bacteraemia. Clin Microbiol Infect. 2012;18:862-869.

79. Townell NJ, Munckhof WJ, Nimmo G, et al. Community-associated methicillin-resistant Staphylococcus aureus endocarditis 'down under' case series and literature review. Scand J Infect Dis. 2012;44:536-540. 
80. Tattevin P, Schwartz BS, Graber CJ, et al. Concurrent epidemics of skin and soft tissue infection and bloodstream infection due to community-associated methicillin-resistant Staphylococcus aureus. Clin Infect Dis. 2012;55:781-788.

81. Shorr AF, Tabak YP, Killian AD, Gupta V, Liu LZ, Kollef MH. Healthcare-associated bloodstream infection: a distinct entity? Insights from a large US database. Crit Care Med. 2006;34:2588-2595.

82. Asai T, Hiki M, Baba K, Usui M, Ishihara K, Tamura Y. Presence of Staphylococcus aureus ST398 and ST9 in swine in Japan. Jpn J Infect Dis. 2012;65:551-552.

83. Klevens RM, Edwards JR, Tenover FC, McDonald LC, Horan T, Gaynes R. Changes in the epidemiology of methicillin-resistant Staphylococcus aureus in intensive care units in US hospitals, 1992-2003. Clin Infect Dis. 2006;42:389-391.

84. Klein E, Smith DL, Laxminarayan R. Hospitalizations and deaths caused by methicillin-resistant Staphylococcus aureus, United States, 1999-2005. Emerg Infect Dis. 2007;13:1840-1846.

85. Chambers HF. The changing epidemiology of Staphylococcus aureus? Emerg Infect Dis. 2001;7:178-182.

86. Gould IM, Reilly J, Bunyan D, Walker A. Costs of healthcareassociated methicillin-resistant Staphylococcus aureus and its control. Clin Microbiol Infect. 2010;16:1721-1728.

87. Klevens RM, Morrison MA, Nadle J, et al. Invasive methicillinresistant Staphylococcus aureus infections in the United States. JAMA. 2007;298:1763-1771.

88. Hanberger $\mathrm{H}$, Walther $\mathrm{S}$, Leone $\mathrm{M}$, et al. Increased mortality associated with methicillin-resistant Staphylococcus aureus (MRSA) infection in the intensive care unit: results from the EPIC II study. Int JAntimicrob Agents. 2011;38:331-335.

89. Thwaites GE. The management of Staphylococcus aureus bacteremia in the United Kingdom and Vietnam: a multi-centre evaluation. PLoS One. 2010;5:e14170.

90. Filice GA, Nyman JA, Lexau C, et al. Excess costs and utilization associated with methicillin resistance for patients with Staphylococcus aureus infection. Infect Control Hosp Epidemiol. 2010;31:365-373.

91. Curtis LT. Prevention of hospital-acquired infections: review of nonpharmacological interventions. J Hosp Infect. 2008;69:204-219.

92. Cosgrove SE, Qi Y, Kaye KS, Harbarth S, Karchmer AW, Carmeli Y. The impact of methicillin resistance in Staphylococcus aureus bacteremia on patient outcomes: mortality, length of stay, and hospital charges. Infect Control Hosp Epidemiol. 2005;26:166-174.

93. Clancy M, Graepler A, Wilson M, Douglas I, Johnson J, Price CS. Active screening in high-risk units is an effective and cost-avoidant method to reduce the rate of methicillin-resistant Staphylococcus aureus infection in the hospital. Infect Control Hosp Epidemiol. 2006;27: 1009-1017.

94. Saavedra-Lozano J, Mejias A, Ahmad N, et al. Changing trends in acute osteomyelitis in children: impact of methicillin-resistant Staphylococcus aureus infections. J Pediatr Orthop. 2008;28:569-575.

95. Murillo JL, Cohen M, Kreiswirth B. Results of nasal screening for methicillin-resistant Staphylococcus aureus during a neonatal intensive care unit outbreak. Am J Perinatol. 2010;27:79-81.

96. Mylotte JM, McDermott C. Staphylococcus aureus bacteremia caused by infected intravenous catheters. Am J Infect Control. 1987; $15: 1-6$

97. Moellering RC Jr. The growing menace of community-acquired methicillin-resistant Staphylococcus aureus. Ann Intern Med. 2006; $144: 368-370$.

98. Moran GJ, Krishnadasan A, Gorwitz RJ, et al. Methicillin-resistant $S$. aureus infections among patients in the emergency department. N Engl J Med. 2006;355:666-674.

99. Yu VL, Goetz A, Wagener M, et al. Staphylococcus aureus nasal carriage and infection in patients on hemodialysis. Efficacy of antibiotic prophylaxis. N Engl J Med. 1986;315:91-96.

100. Stryjewski ME, Chambers HF. Skin and soft-tissue infections caused by community-acquired methicillin-resistant Staphylococcus aureus. Clin Infect Dis. 2008;46 Suppl 5:S368-S377.
101. Tenover FC, McDougal LK, Goering RV, et al. Characterization of a strain of community-associated methicillin-resistant Staphylococcus aureus widely disseminated in the United States. J Clin Microbiol. 2006;44:108-118.

102. Graber CJ, Jacobson MA, Perdreau-Remington F, Chambers HF, Diep BA. Recurrence of skin and soft tissue infection caused by methicillin-resistant Staphylococcus aureus in a HIV primary care clinic. J Acquir Immune Defic Syndr. 2008;49:231-233.

103. Jensen AG, Wachmann CH, Espersen F, Scheibel J, Skinhøj P, Frimodt-Møller N. Treatment and outcome of Staphylococcus aureus bacteremia: a prospective study of 278 cases. Arch Intern Med. 2002;162:25-32.

104. Johnson LB, Almoujahed MO, Ilg K, Maolood L, Khati R. Staphylococcus aureus bacteremia: compliance with standard treatment, long-term outcome and predictors of relapse. Scand J Infect Dis. 2003;35:782-789.

105. Fowler VG Jr, Sanders LL, Sexton DJ, et al. Outcome of Staphylococcus aureus bacteremia according to compliance with recommendations of infectious diseases specialists: experience with 244 patients. Clin Infect Dis. 1998;27:478-486.

106. Liu C, Bayer A, Cosgrove SE, et al. Clinical practice guidelines by the Infectious Diseases Society of America for the treatment of methicillin-resistant Staphylococcus aureus infections in adults and children: executive summary. Clin Infect Dis. 2011;52:285-292.

107. Hersh AL, Chambers HF, Maselli JH, Gonzales R. National trends in ambulatory visits and antibiotic prescribing for skin and soft-tissue infections. Arch Intern Med. 2008;168:1585-1591.

108. Levine DP, Fromm BS, Reddy BR. Slow response to vancomycin or vancomycin plus rifampin in methicillin-resistant Staphylococcus aureus endocarditis. Ann Intern Med. 1991;115:674-680.

109. Siegman-Igra Y, Reich P, Orni-Wasserlauf R, Schwartz D, Giladi M. The role of vancomycin in the persistence or recurrence of Staphylococcus aureus bacteraemia. Scand J Infect Dis. 2005;37: 572-578.

110. Khatib R, Johnson LB, Fakih MG, et al. Persistence in Staphylococcus aureus bacteremia: incidence, characteristics of patients and outcome. Scand J Infect Dis. 2006;38:7-14.

111. Falagas ME, Manta KG, Ntziora F, Vardakas KZ. Linezolid for the treatment of patients with endocarditis: a systematic review of the published evidence. J Antimicrob Chemother. 2006;58:273-280.

112. Thwaites GE, Edgeworth JD, Gkrania-Klotsas E, et al. Clinical management of Staphylococcus aureus bacteraemia. Lancet Infect Dis. 2011;11:208-222.

113. Hiramatsu K, Aritaka N, Hanaki H, et al. Dissemination in Japanese hospitals of strains of Staphylococcus aureus heterogeneously resistant to vancomycin. Lancet. 1997;350:1670-1673.

114. Weigel LM, Clewell DB, Gill SR, et al. Genetic analysis of a highlevel vancomycin-resistant isolate of Staphylococcus aureus. Science. 2003;302:1569-1571.

115. Rybak MJ, Leonard SN, Rossi KL, Cheung CM, Sader HS, Jones RN. Characterization of vancomycin-heteroresistant Staphylococcus aureus from the metropolitan area of Detroit, Michigan, over a 22-year period (1986 to 2007). J Clin Microbiol. 2008;46:2950-2954.

116. Bae IG, Federspiel JJ, Miro JM, et al. Heterogeneous vancomycinintermediate susceptibility phenotype in bloodstream methicillinresistant Staphylococcus aureus isolates from an international cohort of patients with infective endocarditis: prevalence, genotype, and clinical significance. J Infect Dis. 2009;200:1355-1366.

117. Appelbaum PC. Reduced glycopeptide susceptibility in methicillinresistant Staphylococcus aureus (MRSA). Int J Antimicrob Agents. 2007;30:398-408.

118. Hiramatsu K, Cui L, Kuroda M, Ito T. The emergence and evolution of methicillin-resistant Staphylococcus aureus. Trends Microbiol. 2001;9:486-493.

119. Gould IM. Clinical activity of anti-Gram-positive agents against methicillin-resistant Staphylococcus aureus. JAntimicrob Chemother. 2011;66 Supp1 4:iv17-iv21. 
120. Pertel PE, Bernardo P, Fogarty C, et al. Effects of prior effective therapy on the efficacy of daptomycin and ceftriaxone for the treatment of community-acquired pneumonia. Clin Infect Dis. 2008;46: 1142-1151.

121. Miller MH, Wexler MA, Steigbigel NH. Single and combination antibiotic therapy of Staphylococcus aureus experimental endocarditis: emergence of gentamicin-resistant mutants. Antimicrob Agents Chemother. 1978;14:336-343.

122. Wilson WR, Karchmer AW, Dajani AS, et al. Antibiotic treatment of adults with infective endocarditis due to streptococci, enterococci, staphylococci, and HACEK microorganisms. American Heart Association. JAMA. 1995;274:1706-1713.

123. Dworkin RJ, Lee BL, Sande MA, Chambers HF. Treatment of rightsided Staphylococcus aureus endocarditis in intravenous drug users with ciprofloxacin and rifampicin. Lancet. 1989;2:1071-1073.

124. Braun L, Craft D, Williams R, Tuamokumo F, Ottolini M. Increasing clindamycin resistance among methicillin-resistant Staphylococcus aureus in 57 northeast United States military treatment facilities. Pediatr Infect Dis J. 2005;24:622-626.

125. Ruhe JJ, Menon, A. Tetracyclines as an oral treatment option for patients with community onset skin and soft tissue infections caused by methicillin-resistant Staphylococcus aureus. Antimicrob Agents Chemother. 2007;51:3298-3303.

126. Frank AL, Marcinak JF, Mangat PD, et al. Clindamycin treatment of methicillin-resistant Staphylococcus aureus infections in children. Pediatr Infect Dis J. 2002;21:530-534.

127. Gould IM, Cauda R, Esposito S, GudiolF, MazzeiT, Garau J. Management of serious meticillin-resistant Staphylococcus aureus infections: what are the limits? Int J Antimicrob Agents. 2011;37:202-209.

128. Cui L, Isii T, Fukuda M, et al. An RpoB mutation confers dual heteroresistance to daptomycin and vancomycin in Staphylococcus aureus. Antimicrob Agents Chemother. 2010;54:5222-5233.

129. Friedman L, Alder JD, Silverman JA. Genetic changes that correlate with reduced susceptibility to daptomycin in Staphylococcus aureus Antimicrob Agents Chemother. 2006;50:2137-2145.

130. Yang SJ, Kreiswirth BN, Sakoulas G, et al. Enhanced expression of dltABCD is associated with the development of daptomycin nonsusceptibility in a clinical endocarditis isolate of Staphylococcus aureus. J Infect Dis. 2009;200:1916-1920.

131. Morales G, Picazo JJ, Baos E, et al. Resistance to linezolid is mediated by the cfr gene in the first report of an outbreak of linezolid-resistant Staphylococcus aureus. Clin Infect Dis. 2010;50:821-825.

132. Gould IM, David MZ, Esposito S, et al. New insights into meticillinresistant Staphylococcus aureus (MRSA) pathogenesis, treatment and resistance. Int J Antimicrob Agents. 2012;39:96-104.

133. Mediavilla JR, Chen L, Mathema B, Kreiswirth BN. Global epidemiology of community-associated methicillin resistant Staphylococcus aureus (CA-MRSA). Curr Opin Microbiol. 2012;15:588-595.

134. Frenay HM, Bunschoten AE, Schouls LM, et al. Molecular typing of methicillin-resistant Staphylococcus aureus on the basis of protein A gene polymorphism. Eur J Clin Microbiol Infect Dis. 1996;15: 60-64.

135. Bannerman TL, Hancock GA, Tenover FC, Miller JM. Pulsed-field gel electrophoresis as a replacement for bacteriophage typing of Staphylococcus aureus. J Clin Microbiol. 1995;33:551-555.

136. Lee SM, Ender M, Adhikari R, et al. Fitness cost of staphylococcal cassette chromosome mec in methicillin-resistant Staphylococcus aureus by way of continuous culture. Antimicrob Agents Chemother. 2007;51:1497-1499.

137. Collins J, Rudkin J, Recker M, Pozzi C, O’Gara JP, Massey RC. Offsetting virulence and antibiotic resistance costs by MRSA. ISME J. 2010;4:577-584.

138. Deurenberg RH, Stobberingh EE. The molecular evolution of hospitaland community-associated methicillin-resistant Staphylococcus aureus. Curr Mol Med. 2009;9:100-115.

139. Blair JE, Carr M. Distribution of phage groups of Staphylococcus aureus in the years 1927 through 1947. Science. 1960;132:1247-1248.
140. Todd J, Fishaut M, Kapral F, Welch T. Toxic-shock syndrome associated with phage-group-I staphylococci. Lancet. 1978;2:1116-1118.

141. Shands KN, Schmid GP, Dan BB, et al. Toxic-shock syndrome in menstruating women: association with tampon use and Staphylococcus aureus and clinical features in 52 cases. $N$ Engl J Med. 1980;303: 1436-1442.

142. Schlievert PM, Shands KN, Dan BB, Schmid GP, Nishimura RD. Identification and characterization of an exotoxin from Staphylococcus aureus associated with toxic-shock syndrome. J Infect Dis. 1981;143: 509-516.

143. Mato R, Campanile F, Stefani S, et al. Clonal types and multidrug resistance patterns of methicillin-resistant Staphylococcus aureus (MRSA) recovered in Italy during the 1990s. Microb Drug Resist. 2004;10: 106-113

144. Enright MC, Robinson DA, Randle G, Feil EJ, Grundmann H, Spratt BG. The evolutionary history of methicillin-resistant Staphylococcus aureus (MRSA). Proc Natl Acad Sci U S A. 2002;99:7687-7692.

145. Coombs GW, Pearson JC, O’Brien FG, Murray RJ, Grubb WB, Christiansen KJ. Methicillin-resistant Staphylococcus aureus clones, Western Australia. Emerg Infect Dis. 2006;12:241-247.

146. Nimmo GR. USA300 abroad: global spread of a virulent strain of community-associated methicillin-resistant Staphylococcus aureus. Clin Microbiol Infect. 2012;18:725-734.

147. Monecke S, Coombs G, Shore AC, et al. A field guide to pandemic, epidemic and sporadic clones of methicillin-resistant Staphylococcus aureus. PLoS One. 2011;6:e17936.

148. Uhlemann AC, Dumortier C, Hafer C, et al. Molecular characterization of Staphylococcus aureus from outpatients in the Caribbean reveals the presence of pandemic clones. Eur J Clin Microbiol Infect Dis. 2012;31:505-511.

149. Tavares DA, Sa-Leao R, Miragaia M, de Lencastre H. Large screening of CA-MRSA among Staphylococcus aureus colonizing healthy young children living in two areas (urban and rural) of Portugal. BMC Infect Dis. 2010;10:110.

150. Pan ES, Diep BA, Carleton HA, et al. Increasing prevalence of methicillin-resistant Staphylococcus aureus infection in California jails. Clin Infect Dis. 2003;37:1384-1388.

151. King MD, Humphrey BJ, Wang YF, Kourbatova EV, Ray SM, Blumberg HM. Emergence of community-acquired methicillinresistant Staphylococcus aureus USA 300 clone as the predominant cause of skin and soft-tissue infections. Ann Intern Med. 2006;144: 309-317.

152. Rolo J, Miragaia M, Turlej-Rogacka A, et al. High genetic diversity among community-associated Staphylococcus aureus in Europe: results from a multicenter study. PLoS One. 2012;7:e34768.

153. Reyes J, Rincon S, Diaz L, et al. Dissemination of methicillin-resistant Staphylococcus aureus USA300 sequence type 8 lineage in Latin America. Clin Infect Dis. 2009;49:1861-1867.

154. Nichol KA, Adam HJ, Hussain Z, et al. Comparison of communityassociated and health care-associated methicillin-resistant Staphylococcus aureus in Canada: results of the CANWARD 2007-2009 study. Diagn Microbiol Infect Dis. 2011;69:320-325.

155. Montgomery CP, Boyle-Vavra S, Adem PV, et al. Comparison of virulence in community-associated methicillin-resistant Staphylococcus aureus pulsotypes USA300 and USA400 in a rat model of pneumonia. J Infect Dis. 2008;198:561-570.

156. Li M, Diep BA, Villaruz AE, et al. Evolution of virulence in epidemic community-associated methicillin-resistant Staphylococcus aureus. Proc Natl Acad Sci U S A. 2009;106:5883-5888.

157. Kennedy AD, Otto M, Braughton KR, et al. Epidemic communityassociated methicillin-resistant Staphylococcus aureus: recent clonal expansion and diversification. Proc Natl Acad Sci U S A. 2008;105: 1327-1332.

158. McDougal LK, Fosheim GE, Nicholson A, et al. Emergence of resistance among USA300 methicillin-resistant Staphylococcus aureus isolates causing invasive disease in the United States. Antimicrob Agents Chemother. 2010;54:3804-3811. 
159. Cadilla A, David MZ, Daum RS, Boyle-Vavra S. Association of high-level mupirocin resistance and multidrug-resistant methicillinresistant Staphylococcus aureus at an academic center in the midwestern United States. J Clin Microbiol. 2011;49:95-100.

160. Diep BA, Gill SR, Chang RF, et al. Complete genome sequence of USA300, an epidemic clone of community-acquired meticillinresistant Staphylococcus aureus. Lancet. 2006;367:731-739.

161. Ito T, Hiramatsu K, Tomasz A, et al. Guidelines for reporting novel mecA gene homologues. Antimicrob Agents Chemother. 2012;56: 4997-4999.

162. Pantosti A. Methicillin-resistant Staphylococcus aureus associated with animals and its relevance to human health. Front Microbiol. 2012;3:127.

163. Garcia-Graells C, Antoine J, Larsen J, Catry B, Skov R, Denis O. Livestock veterinarians at high risk of acquiring methicillinresistant Staphylococcus aureus ST398. Epidemiol Infect. 2012;140: 383-389.

164. Smith TC, Pearson N. The emergence of Staphylococcus aureus ST398. Vector Borne Zoonotic Dis. 2011;11:327-339.

165. Bhat M, Dumortier C, Taylor BS, et al. Staphylococcus aureus ST398, New York City and Dominican Republic. Emerg Infect Dis. 2009;15: 285-287.

166. van Cleef BA, Monnet DL, Voss A, et al. Livestock-associated methicillin-resistant Staphylococcus aureus in humans, Europe. Emerg Infect Dis. 2011;17:502-505.

167. Meemken D, Blaha T, Tegeler R, et al. Livestock associated methicillinresistant Staphylococcus aureus (LaMRSA) isolated from lesions of pigs at necropsy in northwest Germany between 2004 and 2007. Zoonoses Public Health. 2010;57:e143-e148.

168. Price LB, Stegger M, Hasman H, et al. Staphylococcus aureus CC398: host adaptation and emergence of methicillin resistance in livestock. MBio. 2012;3:e305-e311.

169. Mediavilla JR, Chen L, Uhlemann AC, et al. Methicillin-susceptible Staphylococcus aureus ST398, New York and New Jersey, USA. Emerg Infect Dis. 2012;18:700-702.

170. Foster TJ. Immune evasion by staphylococci. Nat Rev Microbiol. 2005;3:948-958.

171. Bartlett AH, Foster TJ, Hayashida A, Park PW. Alpha-toxin facilitates the generation of CXC chemokine gradients and stimulates neutrophil homing in Staphylococcus aureus pneumonia. J Infect Dis. 2008;198:1529-1535.

172. Kobayashi SD, Malachowa N, Whitney AR, et al. Comparative analysis of USA300 virulence determinants in a rabbit model of skin and soft tissue infection. J Infect Dis. 2011;204:937-941.

173. Bubeck Wardenburg J, Bae T, Otto M, DeLeo FR, Schneewind O. Poring over pores: alpha-hemolysin and Panton-Valentine leukocidin in Staphylococcus aureus pneumonia. Nat Med. 2007;13: 1405-1406.

174. Bubeck Wardenburg J, Schneewind O. Vaccine protection against Staphylococcus aureus pneumonia. J Exp Med. 2008;205: 287-294.

175. Kennedy AD, Bubeck Wardenburg J, Gardner DJ, et al. Targeting of alpha-hemolysin by active or passive immunization decreases severity of USA300 skin infection in a mouse model. J Infect Dis. 2010;202:1050-1058.

176. Wang R, Braughton KR, Kretschmer D, et al. Identification of novel cytolytic peptides as key virulence determinants for communityassociated MRSA. Nat Med. 2007;13:1510-1514.

177. Periasamy S, Joo HS, Duong AC, et al. How Staphylococcus aureus biofilms develop their characteristic structure. Proc Natl Acad Sci US A. 2012;109:1281-1286.

178. Surewaard BG, de Haas CJ, Vervoort F, et al. Staphylococcal alpha-phenol soluble modulins contribute to neutrophil lysis after phagocytosis. Cell Microbiol. Epub March 8, 2013.

179. Chatterjee SS, Joo HS, Duong AC, et al. Essential Staphylococcus aureus toxin export system. Nat Med. 2013;19:364-367.
180. Kretschmer D, Gleske AK, Rautenberg M, et al. Human formyl peptide receptor 2 senses highly pathogenic Staphylococcus aureus. Cell Host Microbe. 2010;7:463-473.

181. Yoong P, Torres VJ. The effects of Staphylococcus aureus leukotoxins on the host: cell lysis and beyond. Curr Opin Microbiol. 2013;16:63-69.

182. Malachowa N, DeLeo FR. Mobile genetic elements of Staphylococcus aureus. Cell Mol Life Sci. 2010;67:3057-3071.

183. Loffler B, Hussain M, Grundmeier M, et al. Staphylococcus aureus Panton-Valentine leukocidin is a very potent cytotoxic factor for human neutrophils. PLoS Pathog. 2010;6:e1000715.

184. Dumont AL, Nygaard TK, Watkins RL, et al. Characterization of a new cytotoxin that contributes to Staphylococcus aureus pathogenesis. Mol Microbiol. 2011;79:814-825.

185. Malachowa N, Kobayashi SD, Braughton KR, et al. Staphylococcus aureus leukotoxin GH promotes inflammation. J Infect Dis. 2012;206: 1185-1193.

186. Morinaga N, Kaihou Y, Noda M. Purification, cloning and characterization of variant LukE-LukD with strong leukocidal activity of staphylococcal bi-component leukotoxin family. Microbiol Immunol. 2003;47:81-90.

187. Alonzo F 3rd, Kozhaya L, Rawlings SA, et al. CCR5 is a receptor for Staphylococcus aureus leukotoxin ED. Nature. 2013;493:51-55.

188. Li M, Du X, Villaruz AE, et al. MRSA epidemic linked to a quickly spreading colonization and virulence determinant. Nat Med. 2012;18: 816-819.

189. DeLeo FR, Kennedy AD, Chen L, et al. Molecular differentiation of historic phage-type 80/81 and contemporary epidemic Staphylococcus aureus. Proc Natl Acad Sci U S A. 2011;108:18091-18096.

190. Mwangi MM, Wu SW, Zhou Y, et al. Tracking the in vivo evolution of multidrug resistance in Staphylococcus aureus by whole-genome sequencing. Proc Natl Acad Sci U S A. 2007;104:9451-9456.

191. Howden BP, Stinear TP, Allen DL, Johnson PD, Ward PB, Davies JK. Genomic analysis reveals a point mutation in the two-component sensor gene graS that leads to intermediate vancomycin resistance in clinical Staphylococcus aureus. Antimicrob Agents Chemother. 2008;52: 3755-3762.

192. Howden BP, McEvoy CR, Allen DL, et al. Evolution of multidrug resistance during Staphylococcus aureus infection involves mutation of the essential two component regulator WalKR. PLoS Pathog. 2011;7:e1002359.

193. Gao W, Chua K, Davies JK, et al. Two novel point mutations in clinical Staphylococcus aureus reduce linezolid susceptibility and switch on the stringent response to promote persistent infection. PLoS Pathog. 2010;6:e1000944.

194. McAdam PR, Holmes A, Templeton KE, Fitzgerald JR. Adaptive evolution of Staphylococcus aureus during chronic endobronchial infection of a cystic fibrosis patient. PLoS One. 2011;6:e24301.

195. Uhlemann AC, Kennedy AD, Martens C, Porcella SF, DeLeo FR, Lowy FD. Toward an understanding of the evolution of Staphylococcus aureus strain USA300 during colonization in community households. Genome Biol Evol. 2012;4:1275-1285.

196. Young BC, Golubchik T, Batty EM, et al. Evolutionary dynamics of Staphylococcus aureus during progression from carriage to disease. Proc Natl Acad Sci U S A. 2012;109:4550-4555.

197. Wertheim HF, Vos MC, Boelens HA, et al. Low prevalence of methicillin-resistant Staphylococcus aureus (MRSA) at hospital admission in the Netherlands: the value of search and destroy and restrictive antibiotic use. J Hosp Infect. 2004;56:321-325.

198. Vos MC, Ott A, Verbrugh HA. Successful search-and-destroy policy for methicillin-resistant Staphylococcus aureus in the Netherlands. J Clin Microbiol. 2005;43:2034; author reply 2034-2035.

199. Graveland H, Wagenaar JA, Heesterbeek H, Mevius D, van Duijkeren E, Heederik D. Methicillin resistant Staphylococcus aureus ST398 in veal calf farming: human MRSA carriage related with animal antimicrobial usage and farm hygiene. PLoS One. 2010;5:e10990. 
200. Kallen AJ, Mu Y, Bulens S, et al. Health care-associated invasive MRSA infections, 2005-2008. JAMA. 2010;304:641-648.

201. Johnson AP, Davies J, Guy R, et al. Mandatory surveillance of methicillin-resistant Staphylococcus aureus (MRSA) bacteraemia in England: the first 10 years. J Antimicrob Chemother. 2012;67: 802-809.
202. Wyllie DH, Walker AS, Miller R, et al. Decline of meticillin-resistant Staphylococcus aureus in Oxfordshire hospitals is strain-specific and preceded infection-control intensification. BMJ Open. 2011;1:e000160.
Clinical Epidemiology

\section{Publish your work in this journal}

Clinical Epidemiology is an international, peer-reviewed, open access journal focusing on disease and drug epidemiology, identification of risk factors and screening procedures to develop optimal preventative initiatives and programs. Specific topics include: diagnosis, prognosis, treatment, screening, prevention, risk factor modification, systematic

Submit your manuscript here: http://www.dovepress.com/clinical-epidemiology-journal

\section{Dovepress}

reviews, risk \& safety of medical interventions, epidemiology \& biostatical methods, evaluation of guidelines, translational medicine, health policies \& economic evaluations. The manuscript management system is completely online and includes a very quick and fair peer-review system, which is all easy to use. 